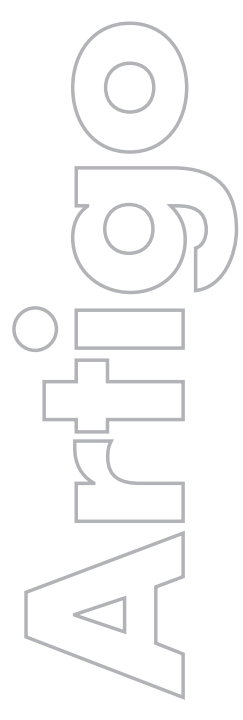

\section{revista}

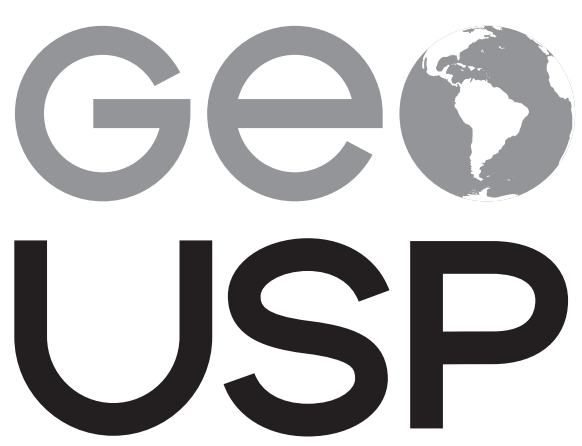

espaço e tempo

Volume $21 \cdot n^{\circ} 3$ (2017)

ISSN 2179-0892
Os territórios da mineração sob a lógica da acumulação financeira no capitalismo contemporâneo

\section{Lisandra Pereira Lamoso \\ UFGD}

p. $718-736$

Como citar este artigo:

LAMOSO, L. P. Os territórios da mineração sob a lógica da acumulação financeira no capitalismo contemporâneo. Geousp - Espaço e Tempo (Online), v. 21, n. 3, p. 718-736, dez. 2017. ISSN 2179-0892.

Disponível em: <http://www.revistas.usp.br/geousp/ article/view/123788>. doi: 10.11606/issn.2179-0892. geousp.2017.123788.

\section{(C) $(1) \Theta$}

Este artigo está licenciado sob a Creative Commons Attribution 4.0 License. 


\title{
Os territórios da mineração sob a lógica da acumulação financeira no capitalismo contemporâneo
}

\section{Resumo}

Os territórios da mineração são espaços utilizados pela indústria extrativa mineral, que tem um significativo protagonismo no processo de acumulação de capital. Tomando como referência a geodiversidade brasileira na mineração, este artigo busca atualizar e aprofundar o debate sobre os processos que comandam esses territórios incorporados à lógica financeira do capitalismo contemporâneo. A pesquisa empregou dados secundários e revisão bibliográfica. $\bigcirc$ artigo mostra que está cada vez mais distante do poder público, em suas diversas instâncias, planejar o setor mineral como parte da estratégia de desenvolvimento econômico. Sob a lógica financeira, as decisões são tomadas pelo mercado de ações, dominado pela expectativa de rentabilidade e distribuição de dividendos, com relevante papel dos fundos de pensão.

Palavras-chave: Territórios da mineração. Acumulação financeira. Indústria extrativa mineral. Fundos de pensão.

\section{Mining territories under the logic of financial accumulation in contemporary capitalism}

\begin{abstract}
Mining territories are spaces used by the mining industry that plays an important leadership role in the process of capital accumulation. Taking as reference the Brazilian geodiversity in mining, this paper aims at updating and deepening the debate on the processes that control these territories embedded in the financial logic of contemporary capitalism. The research employed secondary data and bibliographic review. The article shows evidence that the government, in its various instances, has increasingly lost its power to organize the mining sector as part of the economic development strategy. Decisions, under the financial logic, are taken by the stock market dominated by the expectation of profitability and distribution of dividends, with a relevant role played by pension funds.
\end{abstract}

Keywords: Mining territories. Financial accumulation. Mining industries. Pension funds. 


\section{Introdução}

No território brasileiro, há uma distribuição geográfica diversificada, além de uma farta ocorrência de jazidas minerais, como ferro, caulim, bauxita, cobre e ouro, entre as quais se destacam as jazidas do Quadrilátero Ferrífero de Minas Gerais, a Serra dos Carajás, as jazidas de ouro, em Goiás, e as de manganês, no Mato Grosso do Sul e na Bahia. O Norte do país, em especial o estado do Pará, tem uma das regiões mais "geodiversas" do globo!.

Há regiões nas quais a exploração mineral assume um protagonismo na produção do espaço econômico porque se torna uma atividade que mobiliza a força de trabalho, gera de renda, demanda pela implantação de infraestrutura material e imaterial, forma redes de poder político e econômico, cria e recria fluxos migratórios, gerando consumo de energia e recursos naturais, estabelece uma nova ordem na logística e nos preços das mercadorias e serviços, além de adensar e acelerar a formação de núcleos urbanos que lhe oferecem suporte. A exploração mineral tem uma centralidade no processo de acumulação financeira, formada pelo sistema produtivo, entendido como um conjunto de agentes e relações produtivas que tem lugar sobre um espaço determinado. $\bigcirc$ histórico das explorações é marcado por processos de desestruturação (destruição do ordenamento territorial preexistente, desorganizando a coerência regional interna) e reestruturação (quando faz emergir uma nova organização produtiva, geralmente uma organização industrial original, definida por grandes corporações). $\bigcirc$ espaço usado com essas características é chamado, neste texto, de "territórios da mineração".

Na dinâmica espacial do capital, os territórios produtores de commodities estão diretamente ligados às demandas internacionais, contribuindo com a internacionalização da economia. Não é mais em nível nacional que se determinam as condições de acumulação do capital. A lógica da economia mundial, seguida pelas corporações, produz hierarquias, nas quais determinados espaços (pelas características de extensão e qualidade das jazidas) se tornam mais importantes do que outros e alvo de investimentos. Desta forma, surge uma diferente ordem de desenvolvimento regional que não é mais definida pela demanda nacional, mas sim pela economia mundial. Esses territórios da mineração, estruturados por sua base exportadora e seus efeitos multiplicadores, resultam de conjuntos econômicos de grande dimensão, dotados de tecnologias capital-intensivas, os quais clamam por políticas públicas para dotá-los de funcionalidades que implicam na mobilização de recursos públicos para o suporte da reprodução do capital da atividade mineral. Estes recursos podem ser de forma material e concreta, como serviços de saúde dimensionados para ocorrências de acidentes de trabalho e centros de qualificação de mão de obra; podem também ser de ordem normativa, como leis de incentivo à atividade, isenções fiscais e creditícias, instalando, assim, uma permanente disputa entre projetos de acumulação endógenos e exógenos.

A exploração mineral tem um componente de rigidez locacional, dado pela extensão da jazida e pela qualidade de suas reservas. Contudo, sobre ela pesam também variáveis que não pertencem ao local, uma vez que são forjadas pela demanda externa, pelo preço do minério no mercado internacional, pelos custos de produção e pelos dados da competitividade, em comparação à exploração em outros locais. Os projetos das grandes empresas capitalistas têm maturação de médio e longo prazo. Contudo, o período de implantação que movimenta o aparato de infraestrutura local e que promove fluxos migratórios laborais é curto e intenso, criando contradições entre a produção e a distribuição de riqueza - como não poderia deixar de ser, no sistema capitalista em vigor².

\footnotetext{
1 Tomando por geodiversidade a denominação empregada pelo Ministério das Minas e Energia, numa analogia ao conceito de biodiversidade (Silva; Drummond, 2005, p. 8).

2 Cf. em Palheta da Silva (2002) as implicações da atividade mineral para os municípios na Serra dos Carajás.
} 
No Brasil, há dois territórios de mineração nos quais a atividade mineral, em particular a lavra de minério de ferro, é estruturante na produção do espaço, com maior número de minas de grande porte ${ }^{3}$, bem como representativa da atuação da maior empresa do setor, a Vale. Esses territórios estão no Quadrilátero Ferrífero de Minas Gerais e na região Norte do país, no estado do Pará, Serra dos Carajás, municípios de Parauapebas e Curionópolis (ver Figura 1).

Tanto no Quadrilátero Ferrífero quanto na Serra dos Carajás, a maior exploração individual fica a cargo da Vale, que se destaca pela lavra de minério de ferro (ver Quadro 1). Em Minas Gerais, a produção também é realizada por outras 26 empresas, enquanto no Pará apenas a Vale concentra 63,87\% do total comercializado (com ferro, cobre e níquel). Em Minas Gerais, pouco mais de $71 \%$ do total comercializado está concentrado em 4 empresas: Vale, Companhia Siderúrgica Nacional (CSN), Samarco, MBR e Usiminas (Brasil, 2017a).

\section{Figura 1 - Brasil: localização das minas de ferro no estado do Pará (2015) e de Minas Gerais (2014)}

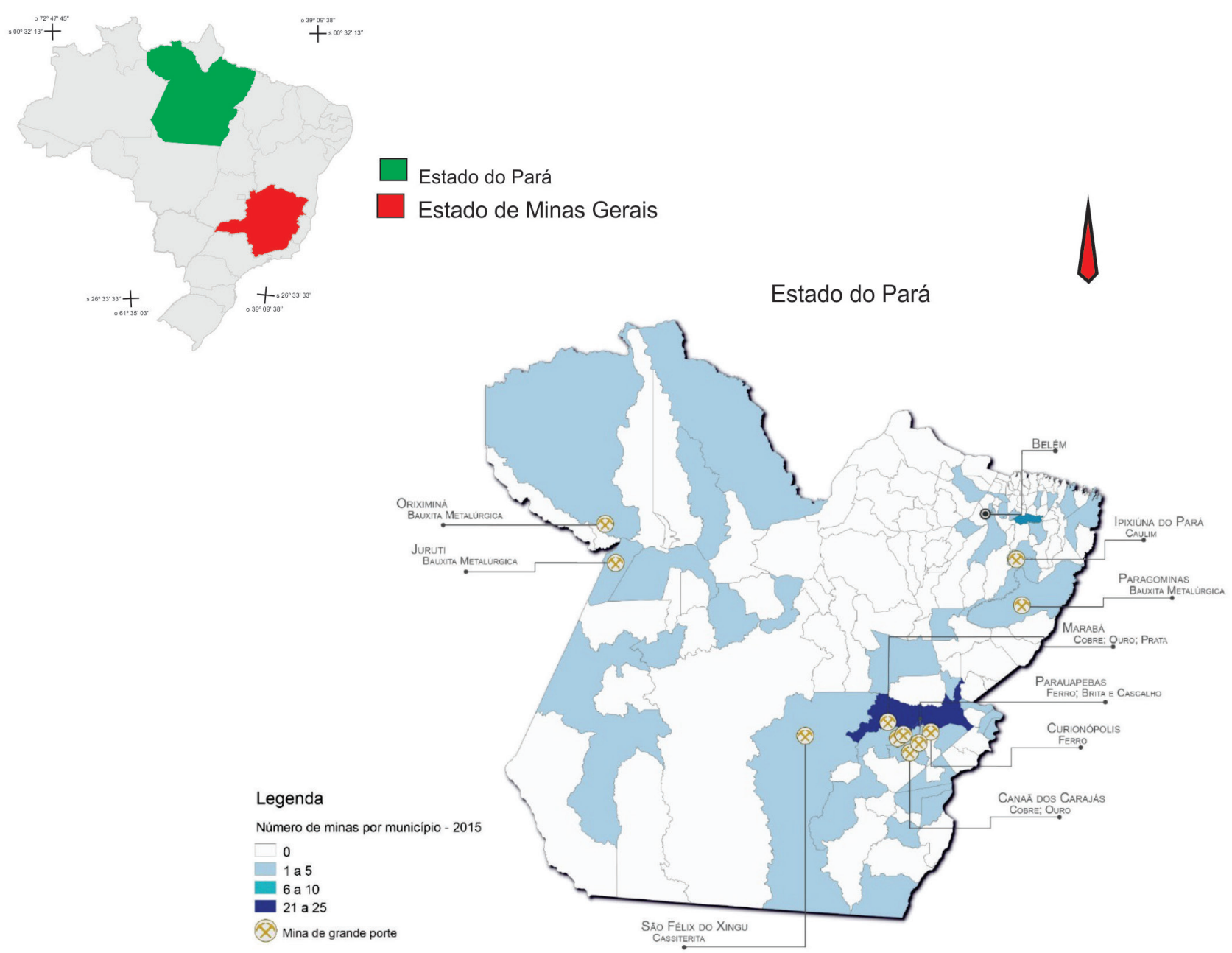

3 Minas de grande porte são aquelas com produção bruta (Run on Mine- $\mathrm{ROM}$ ) anual maior que 1.000 .000 de toneladas. ROM é a extração de minério bruto, sem passar por qualquer tipo de beneficiamento. 


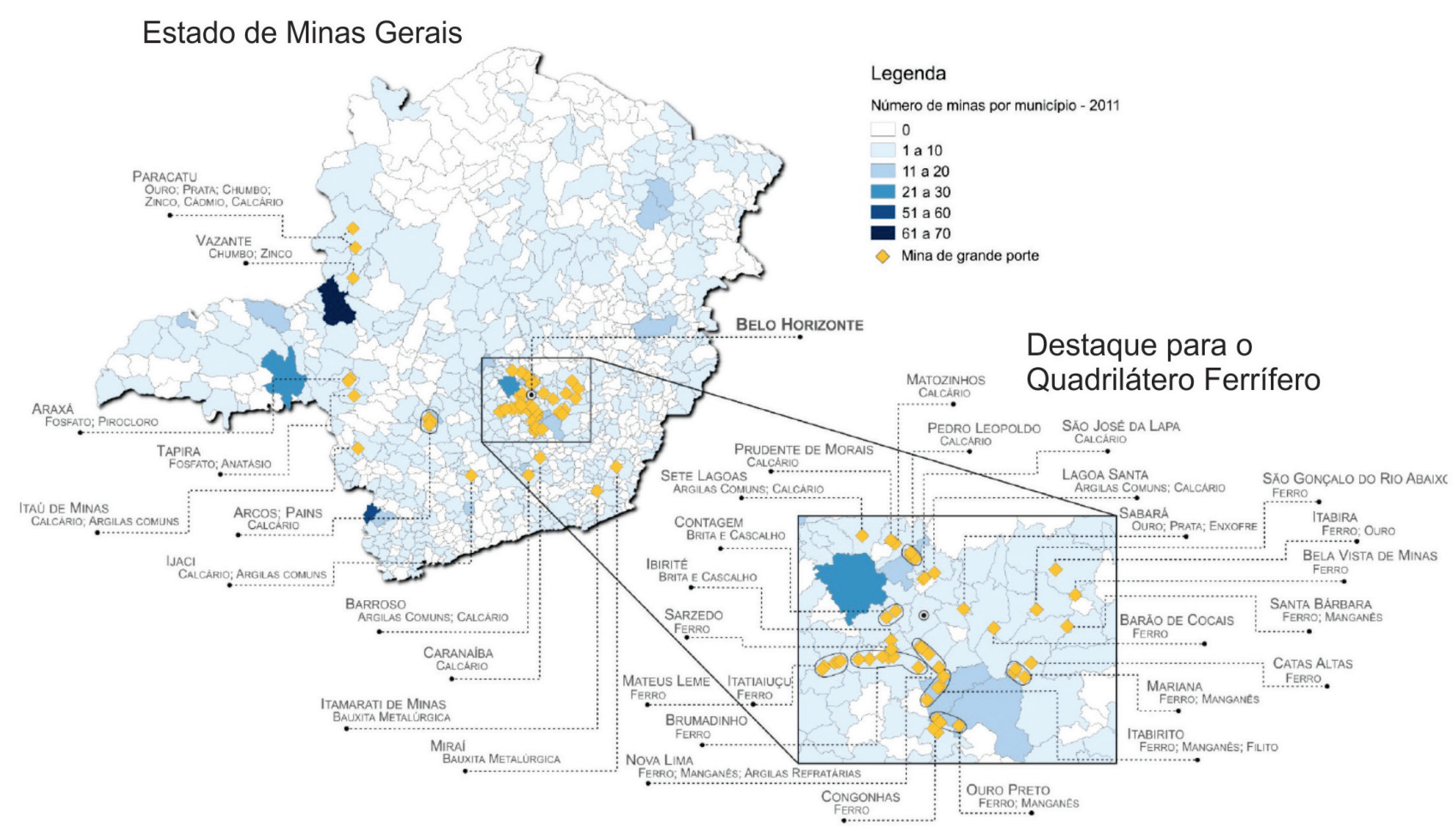

Fonte: Anuário Mineral Estadual de Minas Gerais (2014) e Anuário Estadual do Pará (2015). Organização: Lisandra Lamoso, 2017.

\section{Quadro 1 - Municípios e empresas com lavra de minério de ferro em Minas Gerais (2014) e no Pará (2015)}

\begin{tabular}{|c|c|c|}
\hline UF & municípios & empresas que lavram minério de ferro \\
\hline Minas Gerais & $\begin{array}{l}\text { Barão de Cocais, } \\
\text { Bela Vista de Minas, } \\
\text { Brumadinho, Catas } \\
\text { Altas, Congonhas, } \\
\text { Itabira, Itabirito, } \\
\text { Itatiaiuçu, Mariana, } \\
\text { Mateus Leme, Nova } \\
\text { Lima, Ouro Preto, } \\
\text { Santa Bárbara, São } \\
\text { Gonçalo do Rio } \\
\text { Abaixo e Sarzedo }\end{array}$ & $\begin{array}{l}\text { Vale, Companhia Siderúrgica Nacional, Samarco Minera- } \\
\text { ção, Minerações Brasileiras Reunidas, Mineração Usimi- } \\
\text { nas, Gerdal Açominas, Itaminas Comércio de Minérios, } \\
\text { Nacional Minérios, Vallourec Mineração, Arcelormittal } \\
\text { Brasil, Ferrous Ressources do Brasil, MMX Sudeste } \\
\text { Mineração, Ferro + Mineração, Minerita Minérios Itaú- } \\
\text { na, Herculano Mineração, MIB Mineração Ibirité, SAFM } \\
\text { Mineração, Empresa de Mineração Esperança, Extrativa } \\
\text { Mineral, Anglo American Minério de Ferro Brasil, Mineral } \\
\text { do Brasil, MSM - Mineração da Serra da Moeda, Compa- } \\
\text { nhia de Mineração Serra Azul - COMISA, MTransminas } \\
\text { Minerações, Mineração Marsil, Pedreira Um Valemix, } \\
\text { EMPABRA - Empresa de Mineração Pau Branco e GO4 } \\
\text { Participações e Empreendimentos. }\end{array}$ \\
\hline Pará & $\begin{array}{l}\text { Parauapebas e } \\
\text { Curionópolis }\end{array}$ & 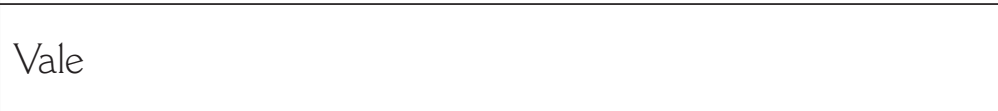 \\
\hline
\end{tabular}

fonte: Brasil (2017a, 2017b).

Sob o ponto de vista da análise econômica, o maior retorno às classes trabalhadoras, moradoras do lugar envolvidas direta e indiretamente na atividade, seria dado pela agregação de valor, de modo a transformar a exploração em uma cadeia produtiva mais densa, com a criação de empregos melhor remunerados, seguidos por um retorno econômico na forma de 
impostos, aplicados no bem público. Esse ciclo não é linear e, invariavelmente, não tem ocorrido na dimensão pretendida. Entre o possível e o concreto há uma complexa teia de mediações e um conjunto de variáveis, os quais buscamos descrever agrupados em uma síntese de cinco fatores: técnico, macroeconômico, normativo, socioambiental e financeiro.

a) Técnico - relativo às especificidades do minério. Por exemplo, quanto ao minério de ferro, a avaliação sobre o seu teor. Quanto às jazidas, o volume conhecido a partir das avaliações que indicam como reserva medida, inferida e estimada ${ }^{4}$. Informações sobre preço, demanda, custos da exploração, logística, transporte e comercialização. São variáveis técnicas que influem na decisão das empresas em verticalizar a cadeia produtiva ou não;

b) Macroeconômico - diretamente ligado à política econômica nacional (oferta de crédito, custo do investimento e taxa de retorno, ambiente macroeconômico de estabilidade política e institucional e orientações de planejamento regional definidas por políticas públicas) e conjuntura econômica internacional (ciclo de preços, geopolítica mineral e estratégias das corporações);

c) Normativo - relativo à elaboração e tramitação dos projetos nas instâncias decisórias, órgãos reguladores, emissores de licenciamento ambiental e até mesmo sistemas de crédito e renúncia fiscal;

d) Socioambiental - derivado da resistência das populações locais ou mesmo de forte pressão dos organismos internacionais aos impactos da atividade, quando os resultados do desequilibrio comprometem os ganhos de médio e longo prazo;

e) Financeiro - esta variável é a protagonista no período da globalização financeira. Nesta, os mercados financeiros geram sua própria valorização, seja ela tanto por meio do capital financeiro quanto pela autovalorização fictícia do capital ${ }^{5}$. Há uma lógica intrínseca ao processo de acumulação, definida pela variável financeira, na qual a "financeirização" ${ }^{\circ}$ da riqueza impõe lógicas "curto-prazistas" determinadas pela remuneração dos acionistas, montante dos dividendos distribuídos, mediados pela administração gerencial dos empreendimentos. A privatização de várias estatais ligadas direta ou indiretamente ao setor mineral nos anos 1990 acentuou o caráter de financeirização da decisão sobre projetos de exploração mineral e verticalização das cadeias produtivas, apesar de que o Estado ainda tem papel importante, por sua capacidade de produzir a legislação da política financeira (Sauviat, 2002/2003).

4 Reserva medida é aquela que foi cubada mediante pesquisas detalhadas. Cubada porque permite avaliar o seu volume com certa precisão, descontando, inclusive, as erosões e falhas ocorridas no corpo mineral. Reserva indicada é aquela avaliada com menos precisão, mediante estudos geológicos de superfície, pouco detalhados ou que foram realizados por uma sondagem pioneira, feita por serviços geológicos do governo ou de organizações particulares. Reserva inferida refere-se àquela que se supõe existir em face da configuração geológica geral de determinadas regiões que são fisiograficamente conhecidas - são informações geológicas.

5 É importante não confundir globalização financeira com capitalismo financeiro. $\bigcirc$ capitalismo financeiro trata de uma fase na evolução do capitalismo como modo de produção, na qual a relação entre a lógica financeira e a produtiva está mantida. Na globalização financeira, os mercados financeiros produzem a sua própria valorização, explicada como autovalorização fictícia do capital ou capital fictício. Para uma discussão mais detalhada, conferir Camargo (2009), que aprofunda a reflexão sobre a supremacia das finanças no capitalismo contemporâneo.

6 Lapyda (2011) discute o emprego do termo "financeirização" por dois autores bastante utilizados pela Geografia, Harvey e Chesnais, obra que pode ser consultada para compreensão das duas análises. 
Este texto pretende discutir algumas implicações da lógica financeira, na produção dos territórios da mineração. A escolha do tema ocorre em concordância com Brandão (2009), quando defende a necessidade de se investigar os novos instrumentos de acumulação e suas sempre renovadas formas de manifestação, por exemplo, da dominância da lógica financeira, bem como com Sokol (2013), que afirma a importância dos períodos de crise econômica para colocar a geografia no centro do debate acadêmico sobre a natureza do capitalismo contemporâneo, inserindo a problemática financeira na discussão.

"Lógica financeira" é um termo bastante amplo que utilizamos para nos referir a um capitalismo que não se limita à valorização dos fatores tradicionais de produção para geração de riqueza, mas que tem acentuada a participação do mercado de ações, do papel do acionista, da distribuição de dividendos; que expõe os investimentos produtivos a um mecanismo cada vez mais externo à possibilidade de controle pela população local e nacional, que é diretamente afetada pelos empreendimentos.

Na primeira seção, apresentamos alguns elementos no intuito de definir características da lógica financeira, mediada pela sociedade de ações. No segundo momento, elaboramos algumas especificidades da exploração mineral para, em seguida, tecer considerações sobre a relação entre finanças e exploração mineral, utilizando exemplos centrados na empresa Vale, que tem sua maior área de exploração mineral no Norte do Brasil (Carajás) e no Quadrilátero Ferrífero, as quais podem ser extrapoladas, com as devidas precauções, para a compreensão de outros territórios de mineração. A construção do texto utiliza alguns aportes selecionados de Marx (1983[1867]), Galbraith (1983[1967], 1988[1973]), Chesnais (1998, 2010), Paulani (2016) e Sassen (2015), além de informações recolhidas na literatura e nos periódicos da mídia impressa e digital especializados em assuntos econômicos?

\section{Lógica financeira e sociedade por ações}

A discussão sobre as finanças deve iniciar pelo reconhecimento de sua importância como viabilizadora de investimentos; como mecanismo que organiza e canaliza recursos para determinado projeto. $\bigcirc$ alargamento da base industrial de produção, com ganhos de escala, foi possível pela intermediação de mecanismos financeiros que aglutinaram a poupança na sociedade por ações, concretizando o que capitais individuais não teriam condições de realizar na mesma escala, em curto tempo. Como ter capital para expandir plantas, custear projetos que são caracterizados por elevado investimento e longos processos de maturação? $\bigcirc$ sistema de crédito, a oferta de ações, o mercado organizado para a participação e atração de fundos de investimento com distribuição de dividendos representaram a organização melhor sucedida em termos econômicos.

A construção teórica elaborada por Karl Marx é uma das maiores contribuições à economia política sobre o sistema capitalista de produção. De acordo com o autor, o aumento da produção, o progresso técnico e a expansão do trabalho assalariado aumentam a demanda

7 Cf., por exemplo, as revistas Brasil Mineral ([s.d.]), Mineração \& Sustentabilidade ([s.d.]) e Minérios $E$ Minerales ([s.d.]) e o jornal Valor Econômico ([s.d.]). 
por mais capital, para o financiamento da produção, desenvolvendo o "capital a juros". Este se realiza em uma órbita própria de valorização que, em seu estágio mais sofisticado, toma a forma de capital fictício. Para Marx (1983[1867], p. 137), "no capital a juros a circulação D-M-D apresenta-se, afinal, abreviada, em seu resultado sem a mediação, por assim dizer em estilo lapidar, como D-D', dinheiro que é igual a mais dinheiro, valor que é maior do que ele mesmo.".

Chesnais (2010), autor que acompanha o pensamento de Marx, enfatiza sobre o caráter exógeno ao processo de produção que o capital portador de juros assume, pois o mesmo é vinculado à mera propriedade deste capital (portador de juros). $\bigcirc$ acionista é importante, visto que a sua remuneração é determinante nas decisões estratégicas sobre como, onde e quanto investir (ou não investir); decisões que são tomadas pela propriedade do capital. A lógica financeira reduz o poder de decisão daqueles diretamente afetados pelos investimentos e enfraquece a autonomia das políticas públicas, tornando-as refém de decisões que beneficiam os acionistas. Nada há de original sobre isso, a não ser a necessidade de atentarmos para o papel que o fator financeiro ocupa nas decisões e como podemos lidar com isso. Lidar significa construir estratégias que administrem a distribuição da riqueza financeira de forma menos concentrada, e isso talvez não possa ocorrer apenas pela via do fortalecimento da sociedade de ações, pois entendemos que esta encontra limites.

Vale (2007) afirma que o curto prazo e o capital especulativo levam as rendas da economia real, embora nada nesse movimento seja absoluto, mediante a possibilidade de processos de resistência política pela organização social em sua mais plena dimensão. Não se pode afirmar a autonomia da esfera financeira sem considerarmos a mediação da disputa que é travada no campo político e que pode subverter a lógica de acumulação financeira, mas para isso é necessário conhecer o peso das finanças e trabalhar nas estratégias adequadas ao enfrentamento. A autonomia da acumulação financeira não é um fato, uma vez que ela está atrelada à esfera material da produção e dos desdobramentos da sua rentabilidade. Os capitais que os operadores financeiros colocam na esfera da valorização, por meio de aplicações financeiras, têm origem no setor produtivo, bem como na produção de valor e de mais-valia (Chesnais, 1998).

Destacamos essa observação de Chesnais porque, no caso da atividade mineral, não pensamos ser adequado supervalorizar a lógica financeira como um processo abstrato que pode desconsiderar a materialidade forjada pela rigidez locacional, pelo tempo de maturação do investimento, pelos riscos elevados, pela incerteza e pelo desenvolvimento tecnológico que tanto aumenta a produtividade, como pode favorecer a substituição de vários tipos de minerais por outros produtos. Essa autonomia há de ser relativizada, contudo, sem desconsiderar as suas características de funcionamento.

As empresas abertas ficam expostas à pressão do mercado de ações e têm que lidar com a expectativa e a cobrança desse mercado, mediando entre investimentos, redução de dívidas e distribuição de dividendos ${ }^{8}$.

8 Há casos em que os próprios executivos que administram a grande empresa também recolhem bônus financeiros, além dos salários. O salário é complementado pela possibilidade de se tornarem proprietários de ações. A valorização das 
Existem vários estudos sobre as características da financeirização. A pesquisa desenvolvida por Allen e Pryke (2013), sobre a financeirização da infraestrutura hídrica no Reino Unido, apontou como a gestão da água reduziu o cidadão, com direitos a um bem básico para sua vida (água), a mero consumidor - usuário de serviços, sendo o serviço de distribuição um ativo financeiro na administração dos recursos hídricos, ou seja, reduzido a um bem de mercado. Em outro estudo, O' Neill (2013) analisou como a financeirização de infraestruturas (como rodovias, aeroportos e telecomunicações) reorganizou os serviços, privilegiando o desempenho financeiro, independentemente da condição de ofertarem boas condições para o fluxo de pessoas nas cidades. A materialidade foi reduzida a uma arquitetura que prioriza produtos financeiros e alavanca créditos sobre os excedentes produzidos pelas atividades econômicas que se utilizam da infraestrutura.

Esta pressão é menos decisiva no setor mineral que lida com expectativas de médio prazo, dado o tempo de maturação dos investimentos. Todavia, ela não deixa de ser um fator determinante na aprovação ou desaprovação dos projetos a serem executados e dos resultados que devem ser obtidos. O caso da empresa Vale (antiga Companhia Vale do Rio Doce - CVRD) ainda é um hibrido, visto que há um importante controle por parte do governo brasileiro sobre as ações preferenciais e da Golden Share', além da influência no voto dos principais fundos de pensão que participam da composição acionária da empresa. São eles: a Fundação dos Economiários Federais (Funcef), da Caixa Econômica Federal, um dos maiores fundos de pensão da América Latina que administra a previdência complementar dos funcionários do banco; a Petros, que administra planos de previdência de entidades e associações de classe, bem como de empresas, entre as quais, a Petrobrás; e a Caixa de Previdência dos Funcionários do Banco do Brasil (Previ).

Um projeto de longo prazo para um país pode ser subvertido por um projeto de governo de quatro anos? O governo ainda mantém influência na administração da Vale por meio do voto dos principais fundos de pensão, os quais têm indicações em consonância com o projeto político de governo e não de Estado. Prestar atenção ao poder de mando dos fundos de pensão, que são os acionistas principais, bem como à orientação dada pela Bradespar - empresa criada em 2000 para administrar as participações não financeiras do Bradesco, que tem ações na Vale - faz parte do necessário reconhecimento da importância da esfera financeira das ações que se materializam nos territórios da mineração mobilizados pela Vale.

Outra autora sobre o tema das finanças, Paulani (2016), afirma que a dimensão da lógica financeira atual deve-se ao fato de que é a posição externa do detentor de ações que comanda

ações em bolsa de valores aumenta o ganho monetário dos executivos presidentes -Chief Executive Officer (CEO). $O$ salário é uma remuneração definida no contrato de trabalho, independentemente do desempenho que a empresa possa vir a ter, enquanto os bônus e as ações são proporcionais ao desempenho da empresa e do executivo.

9 As ações Golden Share são definidas no artigo 17, parágrafo 7॰ da Lei das Sociedades Anônimas - Lei no 6.404, de 15 de dezembro de 1976 (Brasil, 1976). Foi um mecanismo utilizado para manter o controle das empresas privatizadas pelo poder público mesmo quando este não tenha expressiva participação societária em determinada sociedade. No caso da Vale, a Golden Share representa o direito de vetar decisões, como a alteração da denominação social; mudança do objeto social, relativo à exploração de jazidas minerais, e/ou da sede social; e qualquer alienação ou encerramento das atividades de uma ou mais etapas dos sistemas integrados de exploração de minério de ferro. 
as decisões atinentes à produção, não sem antes elencar três importantes observações: 1) Não significa apenas que a valorização financeira é mais importante que a valorização produtiva; 2) Não se trata apenas de afirmar que o crescimento da riqueza financeira ocorre a um ritmo mais elevado do que o crescimento da riqueza real; e 3) Que a valorização financeira tem se autonomizado em relação à valorização produtiva. Paulani sintetiza o regime de acumulação contemporâneo como dominado pela finança, no qual a acumulação não ocorre apenas pela produção, mas tem importância também o capital fictício. Ela ressalta também a essência de um capitalismo rentista, com peso maior dos ativos intangíveis ao invés de trabalho vivo e morto (Paulani, 2016, p. 533).

crédito, o financiamento de longo prazo e o mercado de ações são mecanismos importantes. Considerá-los algo necessário não significa deixar de compreender a extensão de suas implicações. Sassen (2015, p. 135) afirma que "una vez que existen, los beneficios financieros pueden ser considerados moralmente neutros", e que "permanecer inmateriales, utilizados como plataforma para construcciones financieras cada vez más especulativas que llegan a ser tan complejas que desafían el análisis empírico, por no hablar del examen moral.". A dificuldade com a base empírica exige estratégias de pesquisa, pois lidar com finanças implica se deparar com o sigilo das informações ou, não menos importante, com a falta de acesso a elas, o que pode comprometer a nossa capacidade de análise, mas não inviabilizar o reconhecimento da importância estrutural que o componente financeiro tem sobre os territórios da mineração e não apenas sobre eles.

A lógica financeira do capitalismo contemporâneo tem uma expressão espacial. Ela aparece materializada no local, que é parte de um sistema mundial integrado pela internacionalização da economia. Este sistema mundial integrado é composto por estreita dependência entre empresas e sistemas produtivos, de fluxos materiais e imateriais, de estratégias de empresas globais e de especialização e hierarquização das funções produtivas. Há uma crescente dissociação entre os investimentos na exploração mineral de estratégias de desenvolvimento regional. A Vale era um instrumento estatal para as políticas de desenvolvimento regional, tendo sido responsável pela interiorização de infraestruturas, em função das necessidades de sua atividade econômica. A financeirização desatrela essa articulação entre planejamento regional e investimentos produtivos, pois a decisão sobre o investimento ocorre em função do interesse do acionista em benefício de sua maior remuneração. Como realizar um projeto de longo prazo para um desenvolvimento econômico nacional mais autônomo do interesse de curto prazo? Investir em fertilizantes ou na expansão da exploração de minério de ferro, quando esta commodity está com preços em alta no mercado internacional? Reduzir os custos para agricultura nacional ou aproveitar o ciclo de alta no preço do minério de ferro? Se a exportação de minério granulado permite lucros razoáveis, a verticalização da cadeia produtiva é uma decisão de mercado ou de projeto de longo prazo? A exposição à lógica "curto-prazista" tem o tempo de um balancete trimestral, embora na mineração, isso ainda seja relativizado. 
Nos grandes projetos de exploração mineral há um fator material que impõe algumas restrições ao curto prazo. São investimentos de monta que envolvem tempo de maturação, tempo até mesmo para o início da exploração mineral, pois esta é precedida por estudos sobre a localização e dimensão das jazidas e requerem aprovações e licenciamentos em órgãos específicos que deliberam sobre os impactos ambientais.

\section{Os enredamentos da exploração mineral com a lógica financeira}

Os anos 1990 foram parte do terceiro Ciclo Longo da indústria de mineração e de metais da história econômica moderna. Um Ciclo Longo é caracterizado pela alta sustentada no preço dos minérios e metais, em termos reais, acima da inflação. $O$ primeiro Ciclo Longo ocorreu no final do século XIX e início do século XX, determinado pela organização e industrialização dos Estados Unidos. O segundo Ciclo Longo, após a Segunda Guerra Mundial, foi influenciado pela reconstrução europeia, enquanto o terceiro foi estimulado pelo processo de modernização e industrialização da China. $\bigcirc$ ritmo do crescimento chinês está diretamente relacionado ao comportamento do preço das commodities minerais, principalmente o minério de ferro, pela sua direta aplicação como matéria prima de construção civil e bens de capital.

A demanda aquecida no setor mineral ocorreu concomitantemente à fase de implantação das políticas neoliberais no Brasil, quando a saída para a crise econômica foi realizada pela via das privatizações. A reestruturação das estatais teve início no governo José Sarney, com medidas de transferência de empresas para os governos estaduais, alguma privatização (Riocell e Aracruz Celulose, foram as mais importantes estatais privatizadas no período) e duas empresas incorporadas por instituições financeiras. No governo Fernando Collor de Mello (19901992), se intensificou o processo de privatização, com breve desaceleração no governo Itamar Franco (1993-1994) e continuada no governo Fernando Henrique Cardoso (1995-2003). Esse processo de transferência de empresas estatais para a iniciativa privada foi apoiado pelos detentores da dívida pública que estavam interessados nos lucrativos ativos representados pelo patrimônio estatal, em substituição aos bônus públicos desvalorizados que inundavam o mercado (Mamigonian, 1996). Foi o indício de que o "surgimento", ou melhor, o fortalecimento de um novo tipo de poder financeiro era possibilitado por mudanças macroeconômicas e institucionais (Sauviat, 2002/2003), como pode ser exemplificado com as privatizações.

A privatização tornou-se um mecanismo de transferência de patrimônio, dissociada de uma proposta político-econômica de crescimento de longo prazo que se revelou imediatista, na medida em que seu principal objetivo foi o de estabilizar o crescimento da dívida líquida do setor público. Este objetivo ficou explícito quando fora alcançada a redução da dívida imobiliária federal (entre abril e maio de 1997), a partir da aplicação de metade dos recursos da privatização da CVRD (atual Vale).

O setor mineral foi alterado pela privatização da Vale, em 1997. Esta privatização, entre todas as demais, foi a mais desgastante politicamente. Atribuímos esse desgaste à complexidade do empreendimento e ao nível de resistência imposto pelas mais diversas manifestações populares que, embora não tenham sido suficientes para impedir a privatização da empresa, 
colaboraram para evitar a desestatização do Banco do Brasil e da Petrobras, duas das empresas públicas sobre as quais paira, em 2016, o processo de enfraquecimento econômico ${ }^{10}$. Foge ao escopo deste texto detalhar o processo de privatização da Vale. Não obstante, iremos analisar a privatização como elemento-chave na cadeia da lógica financeira. Durante o processo de privatização da Vale, a classe industrial (ou o resquício do que havia restado após a política de abertura às exportações e desnacionalização do parque industrial) se fez representar por meio do Grupo Vicunha (controlado pelas famílias Rabinovich e Vicunha). A composição dos consórcios que concorreram no leilão de privatização revelava uma falta de unidade da classe industrial que entrou dividida na disputa, tendo de um lado o Grupo Votorantim (do empresário Antônio Ermírio de Moraes, prejudicado pela não participação dos Fundos de Pensão) e o Grupo Vicunha (de Benjamin Steinbruch).

$\bigcirc$ jornal Gazeta Mercantil, na edição do dia 10 de junho de 2000, em um parágrafo, sintetizou o conflito entre os grupos industriais e a possibilidade de fortalecimento da esfera financeira:

tradicionalismo, ou o excesso e liquidez dos Ermírio de Moraes, levou-os a desprezar o estratégico apoio dos fundos de pensão. E a falta de apoio, ou de liquidez, motivou Benjamim a correr o risco de seduzir os fundos de pensão a incorporar no projeto o Nations Bank, hoje Bank of America. Depois disso veio o Bradesco que, por não poder participar diretamente do leilão, comprou a franquia do Opportunity que, por sua vez, trouxe o talão de cheques do Citibank. (grifos do autor)

Mais do que tratar de nomes, o trecho da notícia refletiu a correlação de forças que se estabeleceu no comando de uma das mais influentes empresas de mineração, na exploração dos recursos minerais brasileiros.

$\bigcirc$ enfraquecimento de uma participação de cunho industrial/produtivo cedo abriria espaço para que predominassem os interesses financeiros a pretexto do descruzamento das ações da Vale com a CSN. Apenas três anos após a privatização da empresa, no início de junho de 2000, Benjamin Steinbruch foi substituído por Roger Agnelli da presidência do Conselho de Administração da Vale. Essa transição representou um fortalecimento das estratégias financeiras de acumulação na empresa. Agnelli foi representante da nova geração de diretores do maior banco privado do país: o Bradesco, que se tornou acionista da Vale por meio da Bradespar - que, em 2000, já tinha cerca de um bilhão de reais em ativos em empresas como CSN, Globo Cabo, Scopus Tecnologia e VBC Energia.

O desafio de compreender a dimensão da lógica financeira vai ao encontro das caracterís-

10 Em 2016, o Banco do Brasil anunciou o fechamento de 402 agências, a transformação de 379 em postos de atendimento, além do encerramento das atividades de 31 superintendências em vários municípios brasileiros, como medida de reestruturação. Essas mudanças não deixam de representar (sem maior comprometimento de análise) um processo de redução da base de atendimento que não é coberta pela rede bancária privada, o que pode repercutir em ônus aos dependentes dos serviços bancários. Quanto à Petrobrás, esta passa pela maior reestruturação patrimonial e administrativa, com a revisão da partilha na exploração do pré-sal e venda de ativos. 
ticas elencadas por Galbraith (1983[1967]), quando o autor escreveu sobre o "novo capitalismo industrial". Afirma o autor que a grande empresa é regida por burocratas administrativos. As decisões tomadas pelas grandes empresas relativizam o peso dos fatores clássicos, como terra e trabalho, e absorvem as possibilidades de retorno aos acionistas. É de Galbraith (1988[1973]) o destaque para a relação entre as estruturas tecnoburocráticas dos setores privado e público, e como a administração das grandes empresas procura influenciar sistematicamente as políticas públicas ("simbiose burocrática"). A simbiose burocrática, já relatada por Gralbraith, trata da pressão pela nomeação de políticos para importantes cargos decisórios na esfera pública que beneficiam interesses privados. Não são raros os casos de entrelaçamento entre os interesses das grandes empresas de representantes políticos ou de burocratas em exercício. Este é um problema universal que exige mecanismos de aperfeiçoamento dos canais de representação e seleção para os cargos públicos. Se atentarmos para as relatorias de matérias legislativas, podemos recolher alguns exemplos, sobre o lobby na elaboração do Novo Código da Mineração em curso no Brasil ${ }^{11}$.

No caso da Vale, essa simbiose se materializa por meio de representantes do governo nos fundos de pensão que são acionistas da empresa, bem como no poder que estes fundos exercem no apoio, indicação e aprovação do nome do presidente da companhia. A atuação da empresa não decorre de planejamento regional, como acontecia nos anos 1970, interiorizando os projetos de exploração das jazidas na Amazônia Legal'².

Por que a alteração do comando da Vale foi significativa? Não porque o Grupo Vicunha imprimisse um caráter "nacional-desenvolvimentista" à gestão da antiga estatal, mas porque o comando foi orientado para uma gestão em função dos interesses dos acionistas, uma transição entre a lógica financeira/pagamentos de dividendos versus a possibilidade de investimento com retorno de longo prazo. $\bigcirc$ acirramento da lógica financeira representou estratégias de curto prazo focadas na valorização das ações.

É possível exemplificar esta situação quando acompanhamos a relação entre o montante de investimentos e de pagamento de dividendos, realizados pela Vale entre 1996 e 1999 , considerando que 1997 foi o ano da privatização da empresa. Em 1996, a Vale investiu 345 milhões de dólares e pagou de dividendos 249 milhões de dólares; em 1997, foram 669 milhões de dólares para investimentos e 461 milhões de dólares para dividendos; em 1998, foram 480 milhões de dólares para investimentos e 606 milhões de dólares para dividendos; e em 1999 , foram 333 milhões de dólares para investimentos e 481 milhões de dólares para dividendos (Lamoso, 2015) - ver Gráfico 1. A redução dos investimentos serviu para atender os acionistas e investidores que trabalham com o horizonte de balanços trimestrais, prazos extremamente curtos para administrar uma empresa que desde 1942, foi orientada para o trabalho de longo

11 Por exemplo, o fato de a campanha eleitoral do deputado responsável pela relatoria do Novo Código de Mineração ter recebido recursos de empresas de mineração (doações legais e registradas no Tribunal Superior Eleitoral) implica em conflito de interesses, em nosso entendimento. $O$ assunto foi de ampla repercussão na imprensa e em reportagens como "Entidades vão ao STF para destituir relator do Código de Mineração" (Congresso em Foco, 2014) ou "Novo código da mineração é escrito em computador de advogado de mineradoras" (Senra, 2015).

12 Não se trata de avaliação do mérito dos resultados desse planejamento regional, mas do reconhecimento que ele promovia na esfera da política pública de governo, por seus órgãos de planejamento, com direta interferência nos rumos da companhia estatal, que era a CVRD à época, nos anos 1960 e 1970. A fase atual coloca outro vetor com maior peso para decisão de mercado. 
prazo e usada como mecanismo de suporte para o processo de industrialização nacional. Os dividendos representam parte da recuperação do investimento realizado no ritmo imposto pela lógica financeira.

\section{Gráfico 1 - Investimentos e dividendos distribuídos pela CVRD de 1996 a 1999 (em milhões de dólares)}

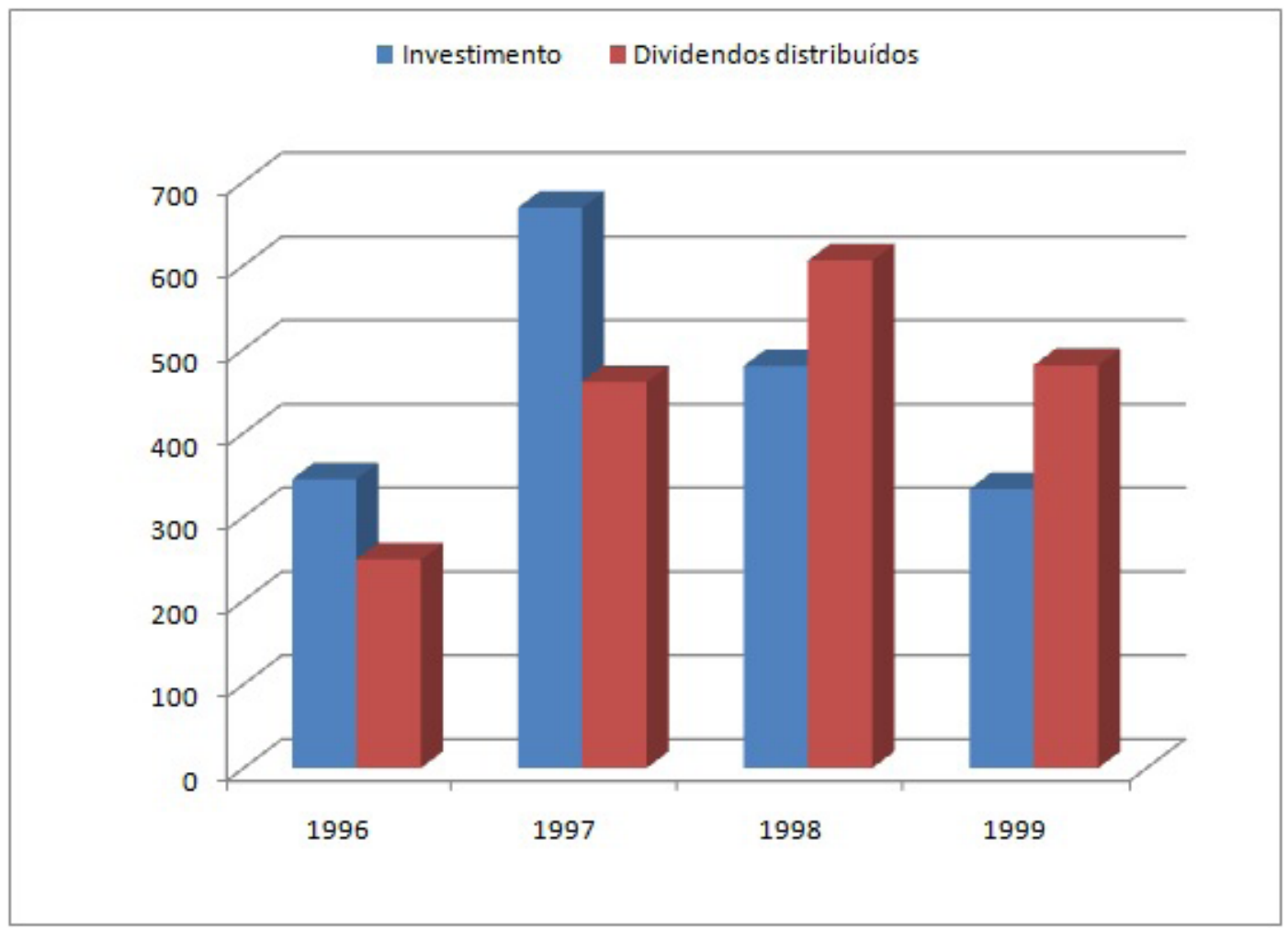

fonte: Lamoso (2015).

Na composição acionária pós-privatização, os fundos de pensão nacionais (como Previ, Petros, Funcef e Funcesp), os fundos estrangeiros e os fundos de investimento diversos (entre eles o Sweet River Fund, do investidor George Soros) assumiram participações na porcentagem das ações ordinárias, aquelas que permitem efetivamente administrar a companhia e definir qual será sua política de atuação. Nas ações ordinárias, também se tornou representativa a participação da BNDESPar, braço do Banco Nacional de Desenvolvimento Econômico e Social (BNDES), com 11\%, no pós-privatização. Nesse ponto, resgatamos o relato oferecido à imprensa pelo ex-presidente do BNDES, Sr. Carlos Lessa, que deixou o cargo em novembro de 2004. Lessa afirmou, em entrevista concedida para a Revista Caros Amigos, em dezembro de 2004, que a CVRD é "estratégica para o Brasil, então não podemos permitir que ela vire uma multinacional". Ao relatar o processo de enfraquecimento político à frente do Banco, depois que autorizou a compra de um lote de ações da empresa pelo BNDES, impedindo que se tornasse uma empresa nipo-brasileira, Lessa revela que "sem avisar ninguém, ganhamos uma fortuna colossal e impedi que a empresa virasse nipo-brasileira. Seria a primeira etapa para ela virar multinacional. Mas, ao fazer isso, construí inimigos pesadíssimos no sistema financeiro, não aqui, lá fora" (Caros Amigos, 2004, p. 35-36). 
Na Figura 2, a composição acionária da Vale em 2017 apresenta a expressão da participação dos fundos de pensão na definição de estratégias pela empresa. Registrando que há participação de sindicalistas nestes fundos, um processo que teve início nos anos 1990 e que se consolidou nos dois governos de Lula da Silva (Zibechi, 2012). A participação de sindicalistas, para Jardim (2007), representou uma tentativa de "moralização e/ou domesticação do capitalismo". Há uma prioridade nessa participação, que é a cobertura de recursos para a previdência social e uma secundária preocupação com a responsabilidade social das empresas nas quais esses fundos investem, tanto que as ações da Vale no caso do rompimento da barragem em Minas Gerais, foram absolutamente protocolares, sem que alguma pressão interna pela parte dos representantes sindicais fosse envidada na priorização da atenção social no tratamento do pós-desastre.

\section{Figura 2 - Composição acionária da Vale (junho de 2017)}

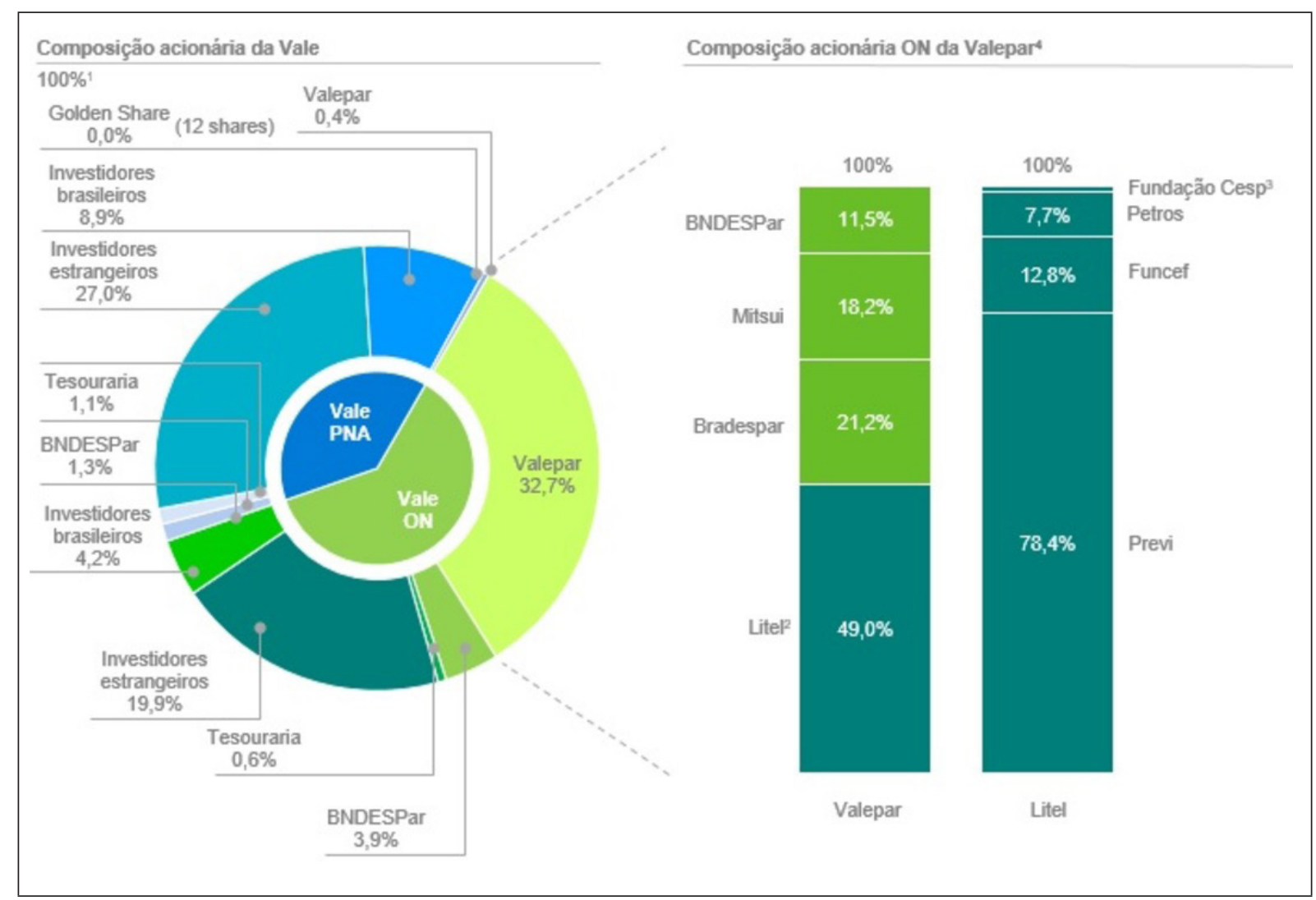

1. Vale $\mathrm{ON}=3,217,188,402$ ações, Vale PNA = 2,027,127,718 ações, Total = 5,244,316,120 ações.

2. Cada membro é um fundo brasileiro de pensão.

3. Percentual da Fundação Cespé de 1.1\%.

4. Baseado em informação disponível no Form 20-F da Vale.

fonte: Vale (2017).

A Vale é uma empresa privada, de capital aberto, com sede no Rio de Janeiro, e com ações negociadas na Bolsa de Valores de São Paulo (BMEFBOVESPA), nas Bolsa de Valores de Paris Euronext, Madrid (LATIBEX) e Nova York (NYSE), integrando o Dow Jones Sector Titans Composite Index. Na Bolsa de Valores de Hong Kong a Vale esteve listada de 2010 até julho de 2016. 
Claude Serfati (1998) afirma que não é mais possível analisar a estratégia e o comportamento dos grupos tomando como base apenas o seu componente industrial. Deve-se também perceber o processo global de valorização de seu capital, atentando-se para as dimensões financeiras do movimento do capital que criam tensões, no interior do grupo, entre as atividades fim e os resultados dos anúncios de dividendos disponibilizados trimestralmente.

A lógica financeira exerce seu poder como antes não o fazia, marginalizando interesses nacionais, embora em alguns momentos Estados e empresas pareçam cerrar fileiras na defesa de interesses comuns. Torna-se indispensável identificar, em cada momento histórico, a configuração das alianças de poder como componente da formação socioespacial.

\section{Considerações finais}

Os territórios da mineração são espaços usados pela indústria extrativa mineral, que exerce um protagonismo significativo no processo de acumulação de capital, envidando processos de desestruturação (destruição do ordenamento territorial preexistente, desorganizando a coerência regional interna) e reestruturação (quando faz emergir uma nova organização produtiva, geralmente uma organização industrial original definida por grandes corporações). Ambos se fazem pela mobilização da força de trabalho, geração de renda, implantação de infraestrutura material e imaterial, formação de redes de poder político e econômico, criação e recriação de fluxos migratórios, consumo de energia e de recursos naturais, estabelecimento de uma nova ordem na logística e nos preços das mercadorias e serviços, aceleração do processo de urbanização, enfim, geração de desequilibrios.

A expectativa de agregação de valor, com redistribuição da riqueza, nem sempre tem sua expectativa atingida. Há um conjunto de fatores que podem ser sintetizados, como técnicos, macroeconômicos, normativos, socioambientais e financeiros, os quais organizam nossa compreensão sobre essas limitações. Entre todos eles, este texto destaca o papel da lógica financeira, que tem subordinado as orientações das políticas públicas para impor uma lógica de mercado nas orientações da exploração mineral.

Os fundos de pensão e acionistas individuais (aqueles com ações que têm direito a voz e voto) que primam por resultados de curto prazo estão ligados ao projeto de governo vigente, por meio do poder de voto de seus representantes nos fundos de pensão e da existência de normas ainda vigentes no mercado de ações, como é o caso da Golden Share para a Vale. Esse "fio de seda" entre o comando da empresa (representado pelos acionistas principais) e o governo pode ser rompido no mercado de ações.

comando empresarial fornece as orientações aos investimentos e desinvestimentos, decide se será mantida a exportação de granulados ou verticalizada a cadeia produtiva, se serão escolhidos fertilizantes para redução de custos da agricultura nacional ou realizados investimentos em commodities, que estão com o preço em alta, ou em prospecção e mapeamento, se será intensificada a exploração em jazidas já conhecidas, expandida a oferta de minérios estratégicos ou aumentada a distribuição de dividendos. São decisões importantes que terão efeitos socioespaciais. 
Não se trata de uma lógica do capital fictício, pois a atividade extrativa é a base material, na qual se ancora a reprodução do capital. Não tratamos de uma órbita própria do circuito de valorização do capital quando nos referimos à lógica financeira e suas implicações nos territórios da mineração. A atenção às finanças decorre da formação de um mercado de ações, e, consequentemente, da expectativa de recebimento de dividendos e valorização por parte dos acionistas. Em relação ao conjunto dos acionistas, no caso pesquisado (que foca a empresa de mineração Vale), ocorre um protagonismo nos fundos de pensão que, ainda e de certa forma, são representantes das orientações de governo. Essa situação de interferência direta nas orientações de governo para a indicação de representantes no conselho de acionistas está definida legalmente pela Golden Share, mecanismo utilizado para viabilizar politicamente o processo de privatização realizado na década de 1990.

Essa estrutura societária de mando, de forma indireta, vai cada vez mais se distanciando da possibilidade de interferência do poder público local (municípios, prefeitos vereadores), regional (executivo e legislativo estaduais) e federal (executivo e legislativo federal), pois as decisões são tomadas pelos dois mercados, de consumo e de ações, assessoradas pelas informações técnicas e operacionais. Qual mineral lavrar, onde lavrar, qual região do país vai receber investimentos, para quais mercados será rentável destinar a produção, se o lucro será reinvestido ou distribuído entre os acionistas são decisões com forte repercussão local, mas tomadas em instâncias que não têm ligação direta ou indireta com a representação popular, salvo movimentos de resistências e enfrentamentos políticos.

É uma lógica que se sobrepõe ao planejamento regional porque ela, sendo necessário, implica em desinvestimentos, desativação ou ativação de sistemas de infraestrutura, com base no retorno financeiro. Utilizar os rendimentos da indústria extrativa mineral para aplicação em ciência e tecnologia, desenvolvimento de sistemas e patentes nacionais e encomendas ao parque industrial brasileiro é uma questão estratégica na pauta do desenvolvimento nacional e, cada vez mais, tomada pelo mercado formado com base na lógica financeira.

\section{Agradecimentos}

À Coordenação de Aperfeiçoamento de Pessoal de Nível Superior (Capes) e ao Conselho Nacional de Desenvolvimento Científico e Tecnológico (CNPq) pelo apoio financeiro.

\section{Referências}

ALLEN, J.; PRYKE, M. Financialising household water: Thames Water, MEIF, and "ring-fenced" politics. Cambridge Journal of Regions, Economy and Society, v. 6, n. 3, p. 419-439, 2013.

BRANDÃO, C. O necessário diálogo entre a economia política do desenvolvimento e a geografia crítica em momento de crise estrutural do capitalismo. In: ENCONTRO NACIONAL DE ECONOMIA POlíTICA, 14., 2009, São Paulo. Anais... São Paulo: Revista da Sociedade Brasileira de Economia Política, 2009. p. 1-23. Disponível em: http://www.sep.org.br/artigos/download?id=1536. Acesso em: 8 fev. 2016. 
BRASIL. Departamento Nacional de Produção Mineral. Anuário Mineral Estadual Pará 2016 - ano base 2015. Coordenação de Marina Marques Dalla Costa et al. Equipe Técnica de Maria do Rosário Miranda Costa et al. Brasilia: DNPM, 2017b. Disponível em: http://www.anm.gov.br/dnpm/publicacoes/serie-estatisticas-e-economia-mineral/anuario-mineral/anuario-mineral-estadual/para/anuario-mineral-estadual-para-2016-ano-base-2015. Acesso em: 4 fev. 2018.

DEPARTAMENTO NACIONAL DE PRODUÇÃO MINERAL. Sumário Mineral - 2015. Coordenação de Thiers Muniz Lima e Carlos Augusto Ramos Neves. Brasilia: DNPM, 2016. Disponível em: http://www.anm.gov.br/dnpm/publicacoes/serie-estatisticas-e-economia-mineral/sumario-mineral/sumario-mineral-brasileiro-2015. Acesso em: 4 fev. 2018.

Departamento Nacional de Produção Mineral. Anuário Mineral Estadual - Minas Gerais - anos base 2010-2014. Coordenação de Marina Marques Dalla Costa et al. Equipe Técnica de Carlos Antônio Gonçalves de Jesus et al. Brasilia: DNPM, 2017a. Disponível em: http://www.anm.gov.br/dnpm/publicacoes/serie-estatisticas-e-economia-mineral/anuario-mineral/anuario-mineral-estadual/minas-gerais/anuario-mineral-estadual-minas-gerais-anos-base-2010-2014. Acesso em: 4 fev. 2018.

. Lei no 6.404, de 15 de dezembro de 1976. Dispõe sobre as Sociedades por Ações. Diário Oficial da União, Brasilia, DF, 17 dez. 1976. Disponível em: http://www. planalto.gov.br/ccivil_03/leis/L6404compilada.htm. Acesso em: 7 fev. 2018.

BRASIL MINERAL. São Paulo, [s.d.]. Disponível em: http://www.brasilmineral.com.br. Acesso em: 4 fev. 2018.

CAMARGO, L. de C. Marx, Keynes e Minsky: a supremacia das finanças no capitalismo contemporâneo. Dissertação (Mestrado em Economia) - Universidade Federal de Uberlândia, Uberlândia, 2009.

CAROS AMIGOS. A proposta de Meireles é liquidar os bancos públicos - entrevista de Carlos Lessa. Caros Amigos, São Paulo, n. 93, p. 32-39, 2004.

CHESNAIS, F. et al. (Orgs.). A finança capitalista. São Paulo: Alameda, 2010.

A mundialização financeira: gênese, custos e riscos. São Paulo: Xamã, 1998.

CONGRESSO EM FOCO. Entidades vão ao STF para destituir relator do Código de Mineração. Notícias, set. 2014. Disponível em: http://congressoemfoco.uol.com.br/noticias/entidades-vao-ao-stf-contra-deputado-leonardo-quintao/. Acesso em: 4 fev. 2018.

GALBRAITH, J. K. A economia e o interesse público. São Paulo: Pioneira, 1988[1973].

O novo estado industrial. 2ed. São Paulo: Pioneira, 1983[1967].

GAZETA MERCANTIL. Gazeta Mercantil. São Paulo, 1 jun. 2000.

JARDIM, M. A. C. Entre a solidariedade e o risco: sindicatos e fundos de pensão em tempos de Governo Lula. Tese (Doutorado em Ciências Sociais) - Universidade Federal de São Carlos, São Carlos, 2007. 
LAMOSO, L. P. A exploração de minério de ferro no Brasil e no Mato Grosso do Sul. São Paulo: Pacco, 2015.

LAPYDA, I. A "financeirização" no capitalismo contemporâneo: uma discussão das teorias de François Chesnais e David Harvey. Dissertação (Mestrado em Sociologia) - Faculdade de Filosofia, Letras e Ciências Humanas, Universidade de São Paulo, São Paulo, 2011.

MAMIGONIAN, A. Estado, privatização e a organização do espaço no Brasil. Informa AGB, São Paulo, 1996.

MARX, K. O Capital. São Paulo: Abril Cultura, 1983[1867]. v. 1, tomo 1.

MINERAÇÃO \& SUSTENTABILIDADE. Betim, [s.d.]. Disponível em: https://revistamineracao.com.br. Acesso em: 4 fev. 2018.

MINÉRIOS \& MINERALES. São Paulo. Disponível em: http://revistaminerios.com.br. Acesso em: 4 fev. 2018.

MONTEIRO, M. de A. Meio século de mineração industrial na Amazônia e suas implicações para o desenvolvimento regional. Estudos Avançados, São Paulo, v. 19, n. 53, p. 187 206, 2005.

O'NEILL, P. The financialisation of infrastructure: the role of language and property relations. Cambridge Journal of Regions, Economy and Society, v. 6, n. 3, p. 441-454, 2013.

PALHETA DA SILVA, J. M. Fragmentação territorial em Carajás. In: SILVA, J. M. P.; SILVEIRA, M. R. da (Orgs.). Geografia Econômica do Brasil. Presidente Prudente: FCT/Unesp, 2002. p. 59-84.

PAULANI, L. M. Acumulação e rentismo: resgatando a teoria da renda de Marx para pensar o capitalismo contemporâneo. Revista de Economia Política, Rio de Janeiro, v. 36, n. 3, p. 514-535, 2016.

SÁNCHEZ PEREZ, J. E. Espacio, economia y sociedad. Madri: Siglo XXI, 1991.

SANTOS, M. Da totalidade ao lugar. São Paulo: Edusp, 2005.

SASSEN, S. Expulsiones: brutalidad y complejidad en la economía global. Buenos Aires: Kutz, 2015.

SAUVIAT, C. Nouveau pouvoir financier et modèle d'enterprise: une source de fragilité systématique. La Revue de 1'IRES, n. 40, p. 38-72, 2002/2003. Disponível em: http:// www.ires.fr/publications-de-l-ires/item/2743-nouveau-pouvoir-financier-et-modele-d-entreprise-une-source-de-fragilite-systemique. Acesso em: 4 fev. 2018.

SENRA, R. Novo código da mineração é escrito em computador de advogado de mineradoras. BBC Brasil em São Paulo, dez. 2015 Disponível em: http://www.bbc.com/ portuguese/noticias/2015/12/151202_escritorio_mineradoras_codigo_mineracao_rs. Acesso em: 4 fev. 2018. 
SERFATI, C. O papel ativo dos grupos predominantemente industriais na financeirização da economia. In: CHESNAIS, F. (Coord.). A mundialização financeira: gênese, custos e riscos. São Paulo: Xamã, 1998. p. 141-181.

SILVA, M. A. R. da; DRUMMOND, J. A. Certificações socioambientais: desenvolvimento sustentável e competitividade da indústria mineira na Amazônia. Cadernos EBAPE. BR, Rio de Janeiro, v. 3, n. 3, p. 1-21, 2005. Disponível em: http://www.scielo.br/scielo. php? script=sci_arttextEpid=S1679-39512005000300003. Acesso em: 16 nov. 2016.

$\mathrm{SOKOL}, \mathrm{M}$. Towards a "newer" economic geography? Injecting finance and financialisation into economic geographies. Cambridge Journal of Regions, Economy and Society, v. 6, n. 3, p. 501-515, 2013.

VALE. Composição Acionária. 2017. Disponível em: http://www.vale.com/brasil/PT/ investors/company/shareholding-structure/Paginas/default.aspx. Acesso em: 12 jun. 2017.

VALE, R. M. G. do. Globalización y organización espacial de la actividad económica. In: ROMERO, J. (Coord.). Geografía Humana: procesos, riesgos e incertitumbres en un mundo globalizado. Barcelona: Ariel, 2007. p. 221-274.

VALOR ECONÔMICO. São Paulo, [s.d.]. Disponível em: http://www.valor.com.br. Acesso em: 4 fev. 2018.

ZIBECHI, R. Brasil potência: entre a integração regional e um novo imperialismo. São Paulo: Consequência, 2012. 